\title{
An Emerging EU Strategic Narrative? Twitter Communication during the EU's Sustainable Energy Week
}

\section{Jessica Bain and Natalia Chaban}

\begin{abstract}
This paper approaches the subject of the global recognition of the term 'Normative Power Europe' in external energy governance by engaging with the concept of strategic narratives. The paper considers reactions to the European Union (EU) as a normative energy actor within a tripartite scheme of strategic narrative formation, projection and reception (Miskimmon et al, 2013; Roselle et al, 2014). The definition of a narrative suggests the presence of an actor, an action, a goal or intention, a scene and instrument. Those were identified for the emerging 'Sustainable Energy Europe' narrative and tested in one empirical case study: Twitter communications surrounding the EU Sustainable Energy Week (EUSEW) 2013. In its method, our analysis is among the first to explore empirically the EU's social media communication efforts. Answering a call for richer methodologies, which view social media data not as 'quantitative data, rather qualitative data on a quantitative scale' (D'Orazio, 2013 np), our analysis uses an original methodology and codes the Twitter data using a nuanced qualitative framework.
\end{abstract}

Key words: EU Sustainable Energy Week, normative power Europe, strategic narrative, Twitter 


\section{Introduction}

As a global energy actor, the actions of the European Union (EU) are guided by a set of norms and principles, which reflect the EU's 'normative identity'. In the field of external energy policies, this identity is exemplified by three norms: security of supply, competitiveness and sustainability, declared in the EU's numerous energy-related policies and the Treaty of Lisbon (see Introduction to this Issue). We approach the subject of the global recognition of the term 'Normative Power Europe' in external energy governance by engaging with the concept of strategic narratives. Narratives are the stories that 'have always shaped the way humans understand the world' (Roselle et al, 2014, p. 74). Strategic narratives are a 'tool for political actors to extend their influence, manage expectations, and change the discursive environments in which they operate' (Miskimmon et al, 2013, p. 2). Through strategic narratives, a polity seeks to be an actor 'other nations listen to, rely on and emulate out of respect and admiration' (Slaughter, 2011, p. 4).

We suggest that a new strategic narrative for the EU - 'Sustainable Energy Europe' is emerging. Classified as an issue narrative - a narrative that is 'seeking to shape the terrain on which policy discussions take place' (Miskimmon et al, 2013, p. 7) - 'Sustainable Energy Europe' is argued to be intimately related to the identity narrative of 'Normative Power Europe' (NPE). Identity narratives are about 'identities of actors in international affairs that are in a process of constant negotiation and contestation' (Miskimmon et al, 2013, p. 7). Defined by Manners (2002) as a peaceful power of ideas and values distinctly different from the aggressive power of economic or military coercion, NPE aims to export a set of norms both internally and externally. Norms are 'collective expectations for the proper behaviour of actors with a given identity' (Manners, 2002). Importantly, norms exported by the EU may trigger a range of reactions from norm receivers, from adoption and adaptation to resistance and rejection (Bjorkdahl et al, 2015). This paper considers reactions to the EU as a normative 
energy actor within a tripartite scheme of strategic narrative formation, projection and reception (Miskimmon et al., 2013; Roselle et al, 2014). This scheme is a part of the most recent theorisation of strategic narratives (Miskimmon et al, 2013) that guides our analysis.

The definition of a narrative suggests the presence of an actor, an action, a goal or intention, a scene and instrument. Those were identified for the 'Sustainable Energy Europe' narrative and tested in one empirical case study: Twitter communications surrounding the EU Sustainable Energy Week (EUSEW) 2013. Our attention towards social media is not accidental. The premise from Castells (2009) that an evolving communications environment is linked to the transformation of how politics works informs our research. Miskimmon et al (2013, p. 4) extend this argument and suggest that online platforms offer 'for the first time, normative models of public spheres and cosmopolitan dialogue'. The key to our analysis is the two-pronged nature of the social media output. On the one hand, it is a media product: a text that may be analysed for its content and 'highlights packaged in selective, framed communications' (Entman 2003, p. 421). On the other hand, it is an evidence of public opinion and public engagement mediated by online media. This two-tale approach allows us to answer the core questions about any strategic narrative: How is it constructed? How is it communicated? How does it flow? And to what effect? (Miskimmon et al, 2013).

The novelty of this paper also lies in its method of analysis, which is among the first to explore empirically the EU's social media communication efforts (see also Koskinen, 2013; Vergeer et al, 2010). For studies of social media, the methodology choices are seemingly limitless. The nature of a platform like Twitter with its sheer volume of available data has encouraged a heavily quantitative, computerised field. D'Orazio (2013) has argued in favour of richer methodologies, which view social media data not as 'quantitative data, rather qualitative data on a quantitative scale' (np). Rather than deploying computational methods, the Twitter data for this analysis were manually coded by a team of trained coders. This 
coders' team enabled a more nuanced look at many of the unique content features of the sampled tweets (see details below).

This paper starts with a delineation of the 'Sustainable Energy Europe' narrative and continues with a consideration of the EU's practice of online communication. We then operationalize the study of the 'Sustainable Energy Europe' narrative in terms of formation, projection and reception, and develop a set of categories for empirical analysis of the EUSEW 2013 Twitter communications. The paper ends with discussion in which we present the emergence and growing appeal of 'Sustainable Energy Europe' strategic narrative and outline future research directions.

\section{EU Strategic Narratives: NPE and 'Sustainable Energy Europe'}

The emerging theory of strategic narratives invites a differentiation between the notions of discourse and narrative, as well as between system, identity and issue narratives (Miskimmon et al, 2013). Discourses are conceptualised as static formations, which do not offer a causeeffect explanation - the 'raw material for communication ... that actors plot into narratives' (Miskimmon et al, 2013, p. 7). Narratives, by contrast, feature a 'causal transformation which take actors from one status quo to another' (Ibid.), with system narratives telling a story how the world is arranged; identity narratives highlighting "identities of actors in international affairs that are in a process of constant negotiation and contestation" (Miskimmon et al., 2013, p. 7) and issue narratives "seeking to shape the terrain on which policy discussions take place" (Miskimmon et al., 2013, p. 7).

We argue that the identity narrative of the 'NPE' - captured by Ian Manners (2002) - is constructed out of the enduring discourse based on a popular, yet contested 'idea of Europe'. This idea is based on historical generation and recognition of particular norms and values as a 
result of a centuries-long tradition of European intellectual innovations. Among those are liberty, freedom of speech, rule of law, human rights, tolerance and democracy.

This discourse arguably informs the NPE identity narrative of the EU, a supranational non-state actor that is active in international relations (IR) and committed to becoming a major global actor. According to Roselle et al (2013, p. 77), a 'strategic narratives employed at one level may affect narratives on the other levels'. We argue that within the 'NPE' script another strong strategic narrative exists in the form of 'Sustainable Energy Europe'.

Theorizing strategic narratives, Miskimmon et al (2013) prescribes the narrative to have an actor, an action, a goal or intention, a scene and instrument. Roselle et al (2104) propose a five member paradigm in a strategic narration: character or actors; setting, environment or space; conflict or action; and resolution or suggested resolution.

While the EU itself is of course the principal actor within our case of energy relations, the story of 'Sustainable Energy Europe' also features a plethora of other EU actors possessing agency and a set of unique characteristics, interests and behaviours. Among these, there is the European Commission with its Commissioners and Directorates-General on Energy, DevCo, Clima, Enterprise, Environment, Research and Trade. These subsidiary actors are responsible for communicating and executing the EU's strategic vision of sustainability globally. In addition, there is also the European External Action Service (EEAS); European Parliament; Council of the EU; EU Delegations, and individual EU member states with their own governments, parliaments, ministries of energy and national diplomatic missions in third countries. The list also includes corporations and transnational companies, as well as business chambers and associations, non-governmental organisations, experts, academia and even general public. One of the defining features of the actors in this narrative is the polyphony in which voices are often not listening to each other.

Energy-related actions by these actors are informed by a set of norms discussed above - security of supply, competitiveness and sustainability. The actions are taking place in a 
number of international settings. Among those, there is International Renewable Energy Agency (IRENA), International Energy Forum (IEF); International Energy Agency (IEA); Energy Charter Treaty (ECT); G-20, Organisation of Petroleum Exporting Countries (OPEC), UN and World Bank. These multilateral representations of the EU's are further complemented by the bilateral, mission-oriented representations through the EU Delegations (EUD). In addition to appealing to the international stakeholders, the actions are also taking place within the EU, among its member states.

The actions are triggered by an on-going conflict, if not crisis, for humanity unsustainable production of energy will lead to strategic and ecological risks, bearing in mind the future impacts of climate change and resource scarcity. As in any good story, the EU has had moments of triumph (e.g. its role in Kyoto Protocol in 2005) and setbacks (e.g. Copenhagen CCC in 2009). It is a dynamic, future-oriented narrative, with a clear causeeffect element to it. Solution of the conflict would warrant a better existence not only for the EU and its citizens, but also for humanity. As such, this narrative has a chance to conquer hearts and minds inside and outside the EU and win over the strategic narratives of other international actors (see also Roselle et al (2014, p. 71) that argue that 'international affairs has become a matter "whose story wins" (Nye Jr., 2013)'. In the increasingly multipolar world, where the power is shifting 'from the West to the rest' and from state to non-state actors, competition for global appeal and dominance of strategic narratives is severe. Shared consensus is highly sought after (Roselle et al, 2014, p. 72). Several international forums, such as the Copenhagen and Durban climate conferences, demonstrated that the EU's conduct in the field of energy policies has risked isolating the EU and leading it to be perceived as a weak actor. Is the EU doing anything to ensure that its narrative appeals globally?

As a global energy actor, the EU possesses an arsenal of instruments, targeting state and non-state actors of international system. State-level instruments on bilateral and multilateral levels remain central. The former level features the EU's Energy Dialogues, 
summits, or sectoral dialogues on the ministerial levels with a focus on energy. The latter level features negotiations during the major multilateral meetings. Instruments also include projects supported by the EU and carried out by third country stakeholders independently or in collaboration with the EU. One of the most recent ones is the 'EU Sustainable Energy Week' (EUSEW), an annual initiative hosted by the EU since 2009. During this weeklong celebration of energy policy and public outreach, the EU hosts over 1000 events. These are aimed at the general public and business, civil society and policy stakeholders, and are intended to promote 'energy efficiency and renewable energy sources in an engaging, accessible and interactive way' (European Union, Sustainable Energy Week 2013). One of the defining features of this initiative is its heavy online presence. This paper focuses on the 'Sustainable Energy Europe' narrative - through Twitter communications during the EUSEW 2013.

\section{Changing Media Environments: Social Media and the EU}

A plethora of state and non-state actors now attempt to partake in International Relations (IR). The proliferation of IR actors on all levels means that the ability to create effective and efficient networks with transparent and speedy flow of information is highly valued. The Internet, and social media within it, has emerged as vital for ensuring effective communication for numerous IR actors. Digital media - with its open and non-hierarchical design - has empowered non-state actors, and even individuals, to influence international relations by directly challenging state actors who used to possess monopoly on the IR. It also provided new powerful instruments for the international actors to maximise the process of 'winning hearts and minds' globally, not least due to a more effective spread of strategic narratives. 
The focus on social media, and in particular on Twitter, in this analysis is key to its significance: with limited exceptions, the vast majority of the literature on the EU's communication deficits focuses on traditional media (among many see: Meyer, 1999; van Noije, 2010; de Vreese, 2004). Yet since its period of reflection and the implementation of 'Plan-D' (Commission, online), the EU has been particularly active in 'new' and social media forms (Badouard and Monnoyer-Smith, 2013). If the empirical evidence suggests that citizens are responding and that there is dialogue and engagement, then this is significant for both the theory and practice of European political communication. This current project is among the first to examine theoretical arguments about the EU's communication competence and more broadly its public diplomacy efforts through the lens of social media.

Issues of legitimacy have long plagued the European integration project (see, among many Beetham and Lord, 1998; Lord, 2000; Verdun and Christiansen, 2000; Eriksen and Fossum, 2002), but such problems have attained a higher profile since the advent of the euro crisis (McCartney, 2013; Bellamy and Weale, 2015). In response to much of this criticism, the two Barroso Commissions were unique in their determination to engage with citizens and encourage participation and dialogue. In addition to creating a DG Communication and an active multi-platform presence, more recently the EU proclaimed 2013 to be the 'Year of the Citizen'. The Commission now hosts its own YouTube channel featuring an array of videos highlighting in advert-length clips the salient points of EU legislation for EU citizens. EU politicians, particularly Commissioners, widely use Twitter. Many of them have followers in the tens of thousands and remarkably, perhaps, many maintain their own Twitter feeds. Facebook groups organised by EU institutions with outreach activities around key issues are also popular. The EU's efforts to engage with individual citizens go far beyond parallel activities by Member States. Clearly with public support for the EU declining (Dendrinou, 2014) and the economic effects of the sovereign euro debt crisis continuing to be felt across the continent (Verdun, 2013), these efforts by the EU are likely to often meet with scepticism 
and ambivalence. But it is no longer true simply to claim, as Longo and Murray have, that the EU has shown an 'inability or unwillingness...to provide the conditions for informed public deliberation on the need for further integration' (2011, p. 669).

Longo and Murray (2011, pp. 671-672) claim that one of the problems with EU efforts at facilitating public dialogues is the lack of bottom-up movements in these; that EU 'sponsored' civil society engagement clouds the very civilian nature of authentic public sphere discussion. Yet empirical literature that explores the relationship between the EU institutions and European citizens via social media is scarce. Kosiken (2013) is one of the few who explores in some detail contributions made by the European Commission via social media and the emergence of English as a Commission lingua franca in these efforts. Our analysis presents a systematic empirical insight into how communications on the EU as a sustainable energy actor are constructed, disseminated and received via Twitter.

\section{Operationalizing Theory: Key Concepts and Methods}

Following Miskimmon et al (2013), this study suggests a comprehensive insight into the phenomenon of strategic narrative by looking into its formation, projection and reception. The three perspectives remain overlooked in the studies of the strategic narratives.

Process tracing is a useful tool for the analysis of the formation of the narrative (complemented by textual analysis and interviews) Roselle et al (2014, p. 78). These elements are instrumental in understanding 'domestic political pressures evident when studying policy narratives' (Roselle et al (2014, p. 78). This paper traces the process around the creation and running of the EUSEW classified here as a public diplomacy initiative, conceived with the intention of raising a positive profile of the EU among different stakeholders in the field of sustainable energy production, research and practice - both within and outside the EU. 
Sustainability is obviously central to EUSEW priorities, but is it achievable and normatively desirable? How does the domestic audience react - does it support or contest sustainability? According to Roselle et al (2014, p. 78), projection of the narrative involves communication of the positions. To study this element involves tracing the narrative flow. In our EUSEW case study, the EU and its actors communicate on Twitter (among other digital locations). However, social media allows communication of the position by all sorts of actors, including receivers of the EU messages. This analysis studies the flow of the narrative between the EU actors and other non-EU actors (state, non-state and individuals). Who is speaking on behalf of the EU? Who else is speaking in the EU? Outside the EU? The data from Twitter was analysed in terms of actors speaking (authors of the tweets) and selective information highlights (frames) present in the texts.

The third, and final element in narrative existence is reception. How is the actor recognised? Is it worth emulating? Is there connectivity between EU/global public and the EU as a producer of the narrative? Do non-EU actors talk to each other bypassing the EU? As discussed above, social media data could be interpreted from two angles: as media content 'highlights packed into selective, framed communications' (Entman 2003, p. 421); and as an evidence of public opinion, public engagement facilitated by the online mediation. This analysis identifies the patterns of connectivity in terms of one-directional messages, dialogic messages and re-tweets (RTs). We also analyse the content of the tweets in terms of who are seen as the most visible actors, what EU norms are perceived to dominate, what issues are recognised by the receivers to top the agenda and what sentiments are seen to guide perceptions toward the EU as sustainable energy actor.

\section{Methods of Analysis}

The data used was a set of Twitter posts from the EU's Sustainable Energy Week 2013, which ran from 24-28 June. ${ }^{i}$ Tweets were included in the sample according to their use of the EU's 
official EUSEW hashtag \#EUSEW13. A total of 2,560 English language tweets were gathered. The decision to restrict the sample to English was made in order to remove the complications arising from translation to and from multiple languages.

While this dataset is small in comparison to the 'big data' analysis typical of Twitter studies (for an overview of the literature see Bruns and Stieglitz, 2013), our choice of manual coding meant restrictions were necessary. Further, while expanding our sampling criteria was considered, our project was eager to hone in on one specific conversation around a unique public diplomacy initiative and thus the decision to limit our criteria was seen as the best choice. The team of coders were trained one-on-one in an intensive weeklong workshop to ensure inter-coder reliability.

Information about the framing categories, energy issues and sentiment categories can be found in the Introduction to this Issue. The authors of each tweet were identified manually through the reading of their public profile. In some cases people who were initially thought to be 'ordinary citizens' were found instead to be linked to a business or interest group. If they were tweeting in their capacity as an employee of such a group, they were then coded accordingly. The N/A category presented in Figure 1 (sources) represents the 'long tail' of Twitter in which the majority of participants are relatively silent, making just one contribution to the conversation, which Vis notes should be factored into any reading of Twitter data (Vis 2013 , p. 33). Due to the manual coding process, and for practicality, only tweet authors who posted more than once were 'coded' into a source category.

This analysis offers a particular methodological innovation in its analysis of sentiment using the tool of conceptual metaphors contained within Twitter dialogues. The majority of sentiment analysis undertaken on social media data utilises computational software like SentiStrength which offer a rigorously tested algorithm for coding sentiment in short text samples (see Thelwall et al, 2011). However, after a pilot test comparing our preliminary manual coding of tweets for sentiment with the results from Sentistrength, it was determined 
that our combination of manually coding for general sentiment as well as the more nuanced sentiment contained within conceptual metaphors would offer a more accurate and richer approach.

\section{Findings}

\section{Formation: Process Tracing of the EUSEW}

As an actor keen to engage with citizens and policy-makers alike, the EU and its representative institutions undertake a vast range of outreach activities. The energy field is no different. The EUSEW was created with a view to facilitate networking and bring together key participants, since 'one of the EU's priorities in all policy areas is to facilitate the sharing of ideas and best-practises, and to encourage networking and exchange, to support the replication of successful projects across Europe' (European Union 2013, np.). As with all EU events and activities now, social media plays an important role in facilitating the public outreach and engagement, as was the case for EUSEW13. This project chose to focus its attention on the Twitter account 'EU Energy Week', username @euenergyweek. Energy Week was conceived as a platform to profile and reward excellence in the field of sustainable energy. From its inception in 2009, the initiative was organised by the EU to 'encourage a bottom-up approach', in line with the EU's broader goals of making itself more accessible and transparent to its citizens and stakeholders. While the events are primarily focused on the EU, the EUSEW is designed to involve participants from non-EU partners, and although the primary focus of EUSEW is on sustainability, we can see from the EU's press releases evidence that the EU's 'normative energy triangle' of frames is embedded throughout: sustainability is highlighted but the benefits of this for economic growth and competitiveness are routinely noted, as are alternative energy sources which can help secure Europe's energy future (see http://europa.eu/rapid/press-release_MEMO-13-596 en.htm). 


\section{Projection}

Insight into who communicates the position is one of the key elements in the analysis of the projection element of a strategic narrative. We first identified the authors of EUSEW tweets as this category highlights who was speaking to/from the EU and which EU representatives were most vocal during this particular energy-related week. The findings can be seen in Figure 1.

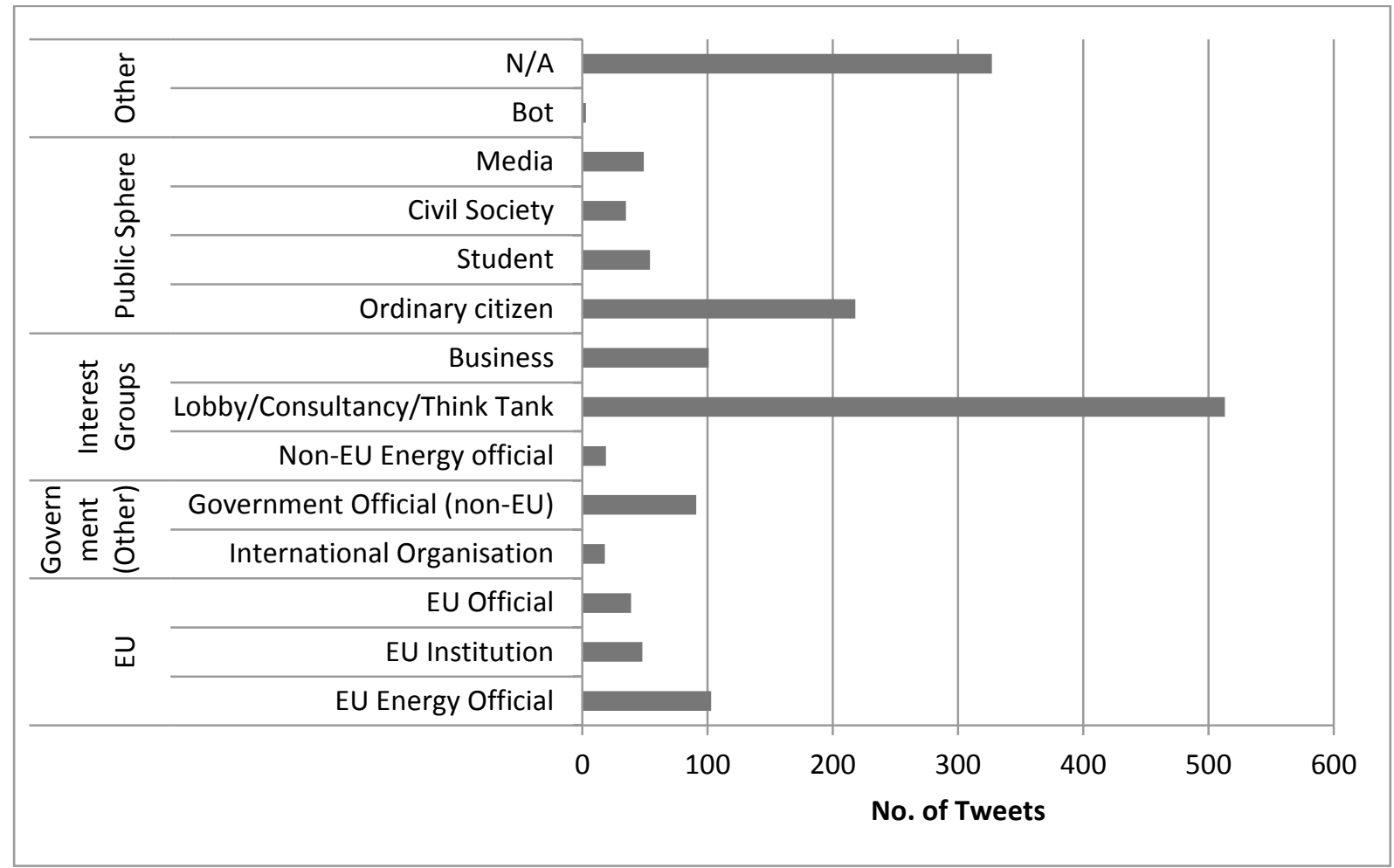

\section{Figure 1: Author Categories of EUSEW Tweets}

Figure 1 gives some insights into the nature of the conversation on the EUSEW. Interest groups - a category that included lobbyists, think tanks and consultancies - dominated the Twitter conversation during our period of analysis. This result is unsurprising since these organisations and groups often have dedicated Public Relations (PR) and communication staff as well as social media managers and are thus effective social media 'players', and the EU has 
one of the most complex and strong lobby environments in the world, with an estimated 30,000 lobbyists working to influence legislation in Brussels (Traynor, 2014).

Notable is both the limited number of EU-related authors and the relatively high volume of 'ordinary citizens' involved in the conversation. While the numbers are much smaller than the combined lobby numbers, still the above chart does indicate that there is a level of engagement with the EU by ordinary, interested people. We argue that this result challenges the notion that the public are disengaged and disinterested in EU affairs. It also suggests that the narrative of 'Sustainable Energy Europe' is indeed appealing to citizens.

Twitter offers perhaps the most direct form of democratic engagement for citizens interested in EU politics - a space where individuals can genuinely engage in a one-on-one basis with political matters. However, mass media (individual journalists and news outlets) do not appear to share that interest or engagement. In this example, we see a replication in the social media world of a problem the EU has long suffered in the mass mediated world: a lack of interest by the mainstream media in its supposedly complex and bureaucratic affairs (Burton, 2005).

Projection was also examined on the level of the selected communication highlights frames - that surfaced when communications on the EU energy issues took place (Figure 2). Importantly, even in a conversational space as limited as Twitter, discussions of politics and economy were seldom discussed as single issues and multiple frames were observed in individual examples.

[Figure 2 about here]

\section{Figure 2: Frames of communications in EUSEW Tweets}




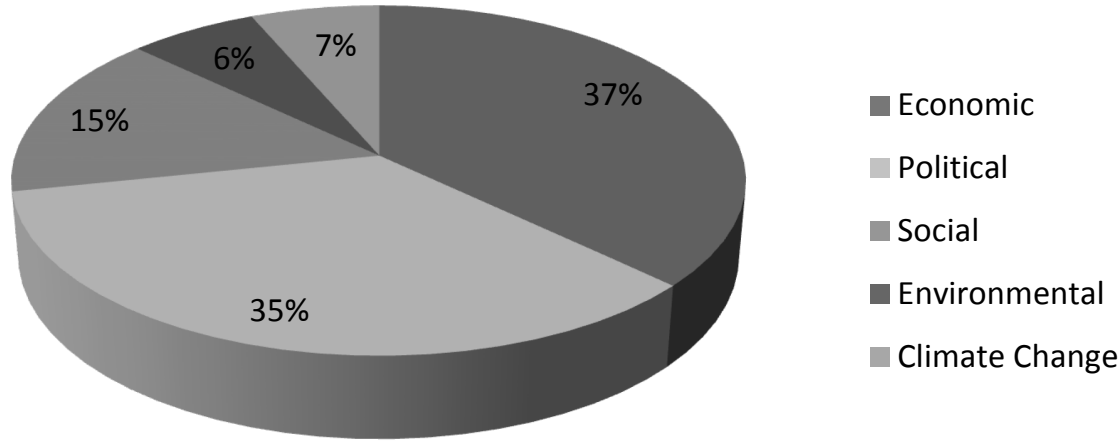

A predominance of business and political concerns is again, unsurprising. But it is noteworthy that there were only limited volumes of climate change and environmental concern apparent when EU positions were communicated in the Tweets. It indicates that when the EU's energy matters are discussed, the political and economic advantages or challenges posed by its energy actions strongly shape the conversation. These efforts then ultimately shape a normative agenda and we see the EU emerge as a leader in, for example, gender equality law. Perhaps a similar effort is under way in terms of shaping 'Sustainable Energy Europe' narrative. A normative strength emerges, but it uses economic pragmatism as the driver.

\section{Reception}

Tracing the flow of communication further, this study found a significant share of RTs (over 900 in a 2560 size sample). The EU was not observed to tweet and then engage in discussion in this particular case. Empirical observations instead bring forward a promotional, shouting or sharing type of conversation on Twitter around EUSEW - one-off comments that were communicated and sometimes shared (retweeted). This phenomenon is relatively typical on Twitter, owing to its particular structure that disperses conversation through an often diverse network (boyd et al, 2010). In their study of the conversational patterns on Twitter, boyd et al 
have noted that in Twitter, 'Many people may talk about a particular topic at once, such that others have a sense of being surrounded by a conversation, despite perhaps not being an active contributor. The stream of messages provided by Twitter allows individuals to be peripherally aware without directly participating' (2010, p. 1, emphasis added). This conceptualisation enables us to view retweeting as a form of information diffusion and participation and thus we view the 'spreading and sharing' of EUSEW tweets as more than just 'throw away' comments, but rather as an important way of validating the messages (boyd et al., 2010) and potentially engaging with others (who receive but may not distribute the messages themselves).

Another element in our analysis of reception was the actors who were under discussion. How visible were EU energy actors in the EUSEW Twitter dialogue? Which other actors were prominent and what does this tell us about how the EU is represented in social media conversations about energy policy? Figure 3, below reflects the findings of this category.

[Figure 3 about here]

Figure 3: Actors Mentioned in Tweets about EUSEW13 


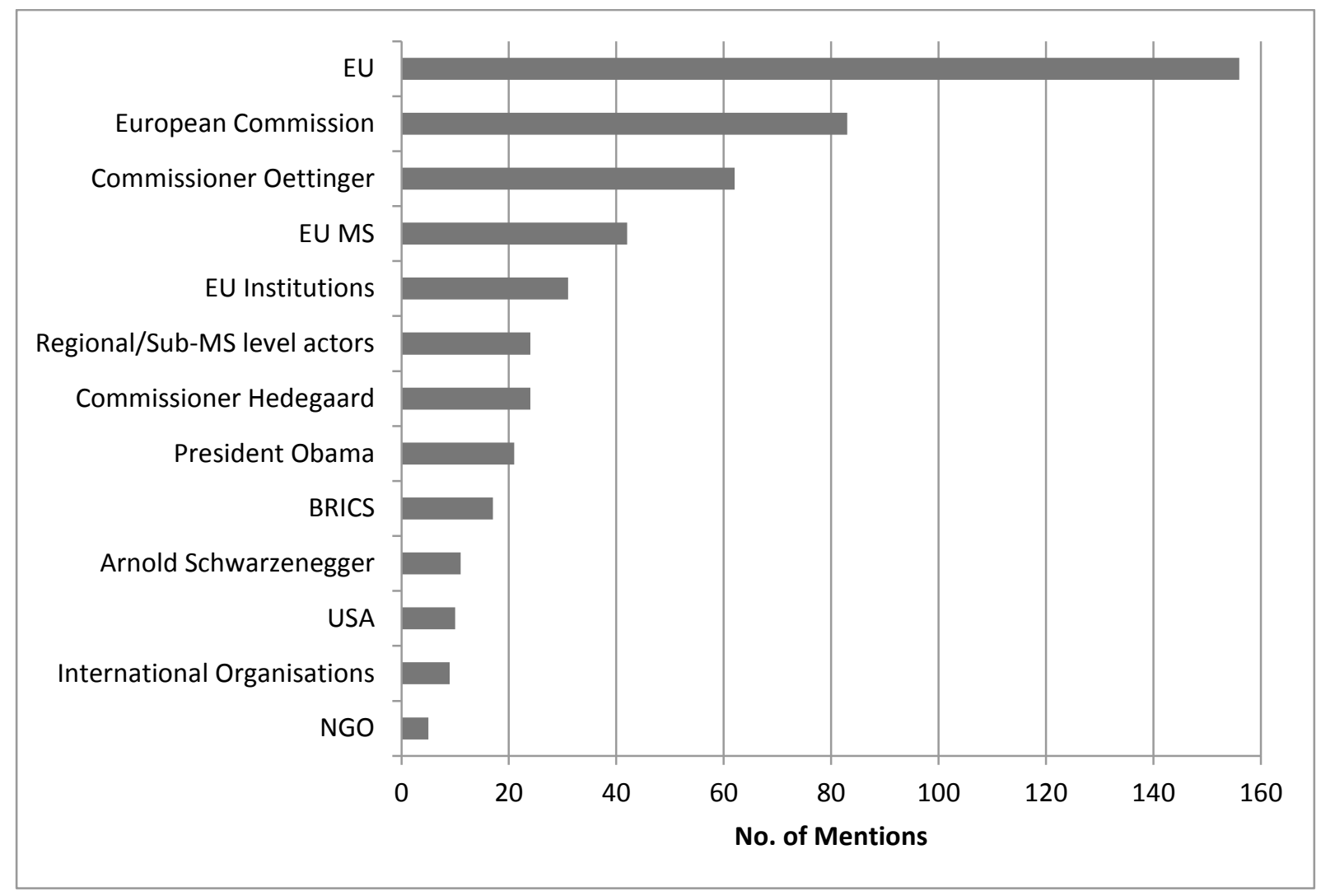

A list of over 200 different individual actors was identified and Figure 3 presents only the top 13 categories perceived to be acting. For ease of discussion, we have in some cases grouped together certain types of actors. ${ }^{\text {ii }}$ The visibility of the EU as a whole is not surprising and the numbers in Figure 3 concern only additional mentions of the EU; obviously every tweet in our sample included the hashtag \#EUSEW13 which already contains reference to the EU itself: the above Figure indicates EU mentions in addition to this. The Commission is dominant, as are its two most prominent representatives (former Commissioners responsible for energy (Gunter Oettinger) and for climate change (Connie Hedegaard). There are some surprises, most notably the visibility of Arnold Schwarzenegger: the film star and Governor of California has been a prominent activist in the field of energy sustainability in recent years and his involvement in the EUSEW events was high profile, trumping references to the whole of the United States. 
Figure 3 shows that EU actors were highly visible. We suggest that this indicates a growing recognition of the EU and its actors as the protagonists in the narration of the strategic story 'Sustainable Energy Europe'. The lack of diversity is perhaps most concerning from a public diplomacy angle since there is evidence that the EU is not engaged beyond its borders. Despite its claimed goals, this event was seen in the Twittersphere as an internal concern for Europe.

Our analysis of the reception also examines which EU norms are seen as influencing global conversations around energy. As such, the EUSEW tweets were coded for the three frames informing this Issue: sustainability, competitiveness and security of supply. Given the focus of the event itself on sustainability, it was unsurprising to find a predominance of the sustainability frame, as seen in Figure 4. This finding suggests that there is a growing recognition of the issue narrative 'Sustainable Energy Europe' linked to the supranational normative narrative 'NPE'. The EU's normative influence in the sphere of energy policy resonates in the reception of the sustainability frame, arguably creating a picture of the EU as an actor inextricably linked with sustainability concerns.

\section{Figure 4: Energy Frames in EUSEW Tweets}




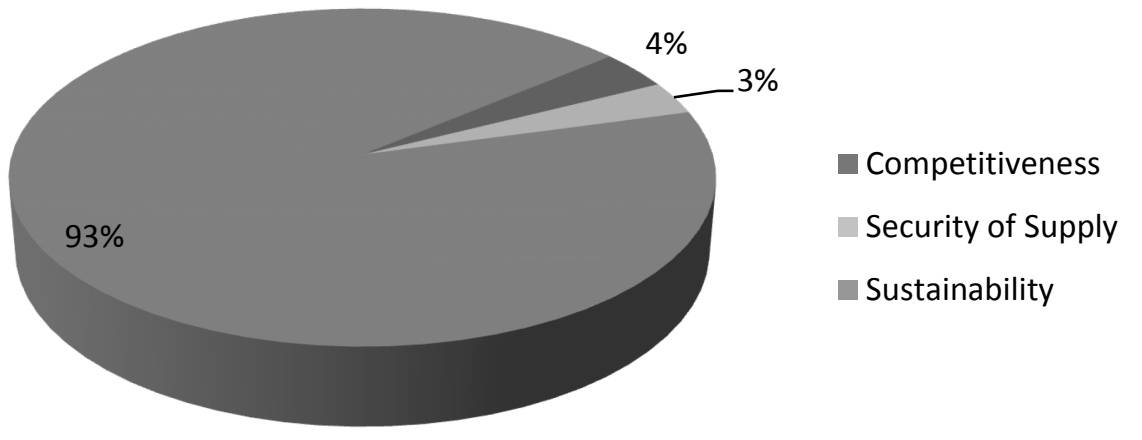

How exactly the topic of energy is discussed in Twitter by involved parties was of particular interest in this paper. In what areas of energy policy is the EU seen to play a role? Figure 5 highlights the specific energy issues that shaped the Twitter discussion of the EUSEW. Mostly likely reflecting the interest groups involved (many of whom would have run or participated in specific public events during the EUSEW), tweets that focused solely on EUSEW public events were the biggest energy issue identified. However, taken together, the next two issues - sustainable development and energy efficiency - received a higher volume of tweets. The two issues reflect specific concerns with the global energy agenda that the EU has sought to shape for a number of years - and are arguably reflected in the emerging strategic narrative of 'Sustainable Energy Europe'. Addressing the EU's own energy security is often seen to be intertwined with a plan for sustainable development and cutting energy wastage that seems to resonate with the EUSEW Twitter audience.

[Figure 5 about here]

Figure 5: Energy Issues Shaping Twitter Discussions of EUSEW13 


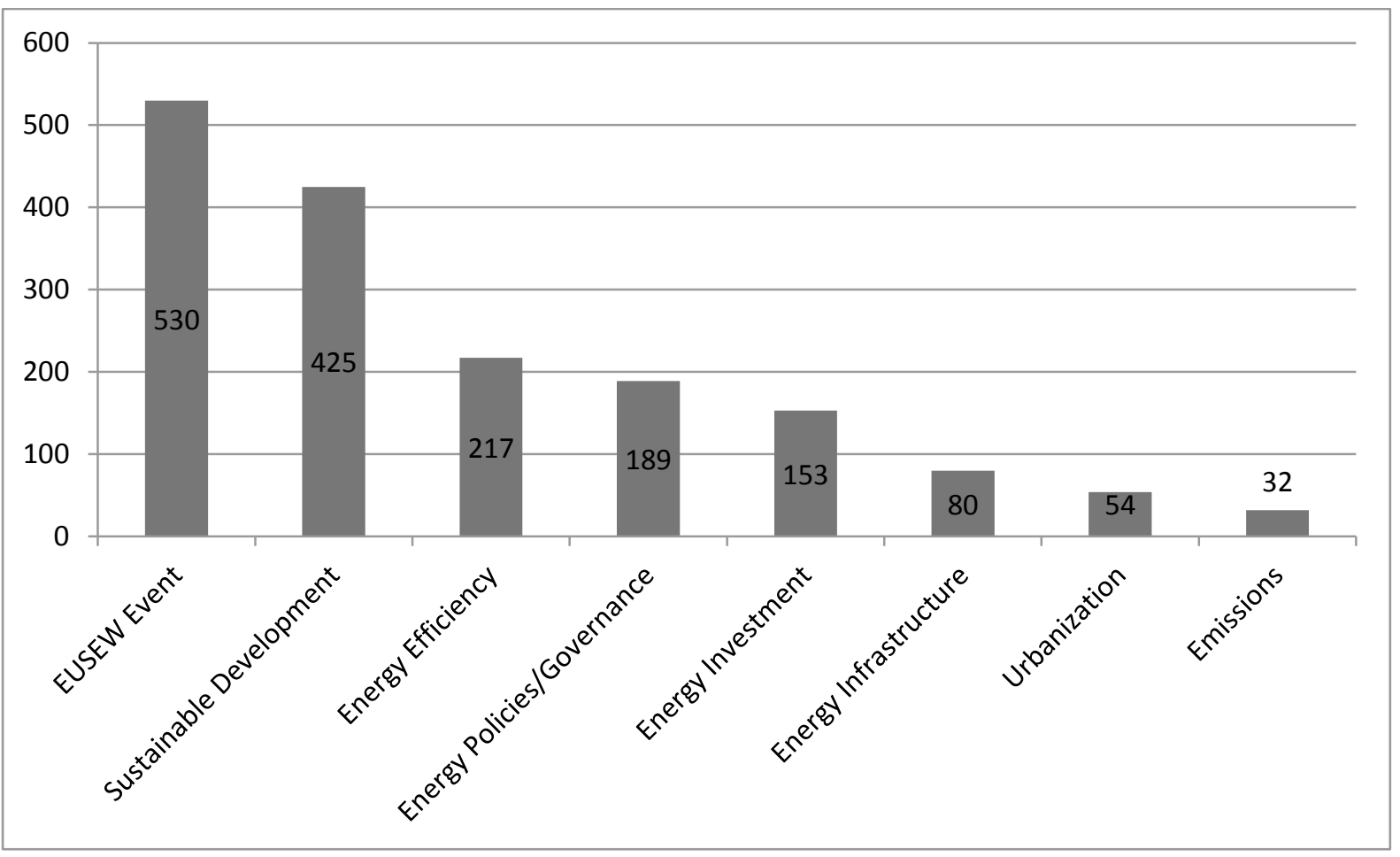

Owing to our use of conceptual metaphors as an additional qualitative device in measuring sentiment, our study is able to detect a much more nuanced degree of sentiment. We argue that the complexity of language is heightened in a space as restricted as Twitter and thus the value and power of linguistic devices like metaphor are strengthened. Importantly for our focus on the strategic narratives, metaphors are seen to be capable of 'trigger[ing] and/or shap[ing] narratives' (Miskimmon et al, 2013, p. 7). Figure 6, presents the results of the sentiment analysis of our Twitter sample on EUSEW.

Neutrality is the largest proportion. On a topic like the EUSEW, and indeed in discussions of policy generally, it is unsurprising to find a high level of neutrality. Many tweets relating to our topic were simply advertising/PR messages promoting a specific EUSEW event, and oftentimes such tweets were entirely neutral. However, it is in the more nuanced levels of sentiment where we begin to see an interesting picture. As can be seen in Figure 6, neutral-to-positive and positive tweets far outweighed the volume of negative ones. It might be that those who are actively engaged in the initiative have come with more positive 
views because they have an interest. They are likely to be supportive. In more general studies of the EU's Twitter communication, a higher level of negativity is probable, given the levels of societal Euroscepticism. In this case, we observed strong evidence of a positive image of the EU as an energy actor involved in sustainable energy issues. This finding may be another indicator that narrative 'Sustainable Energy Europe' is able to elicit positive attitudes from the participants in communication - yet another promising sign of an emerging narrative.

[Figure 6 about here]

\section{Figure 6: Sentiment Stance of EUSEW Tweets}

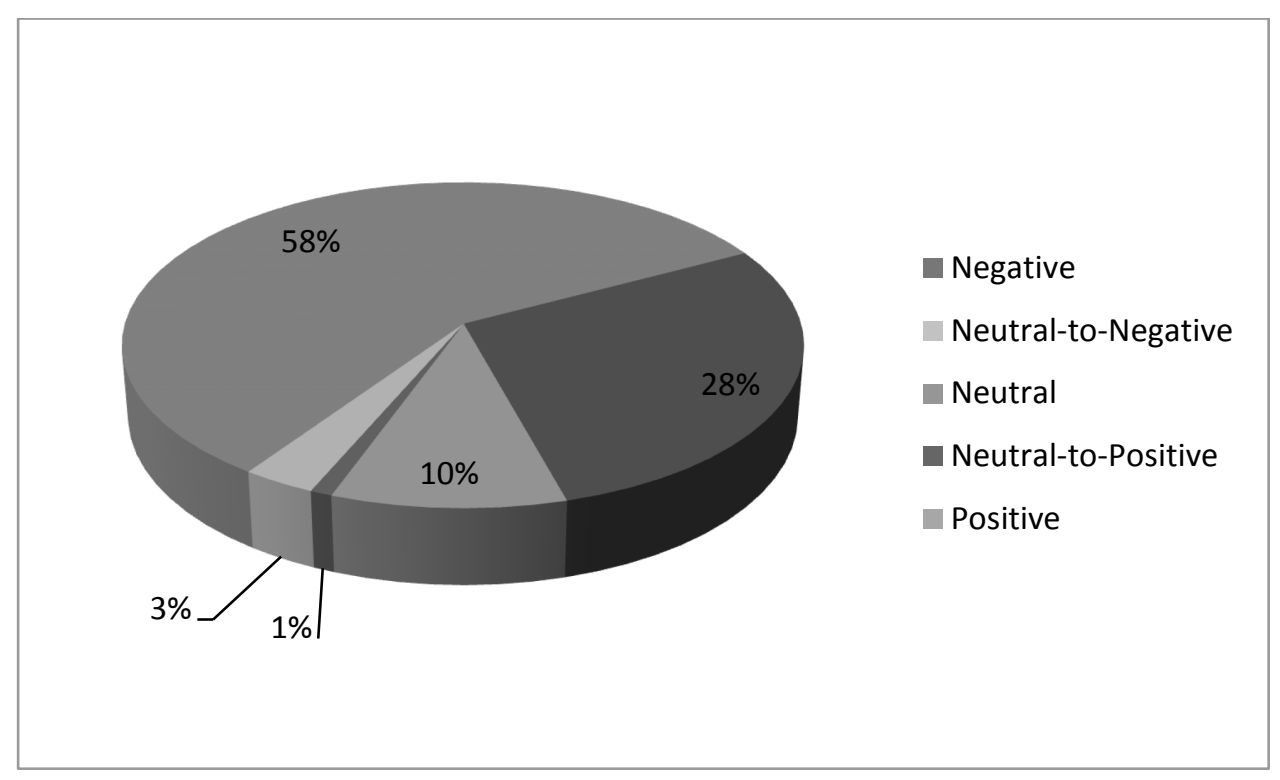

Within each of our sentiment categories, there were a number of conceptual metaphors identified. Figure 7 presents distribution of metaphors according to the expressed sentiment.

[Figure 7 about here]

Figure 7: Volume of Conceptual Metaphors according to Stance 


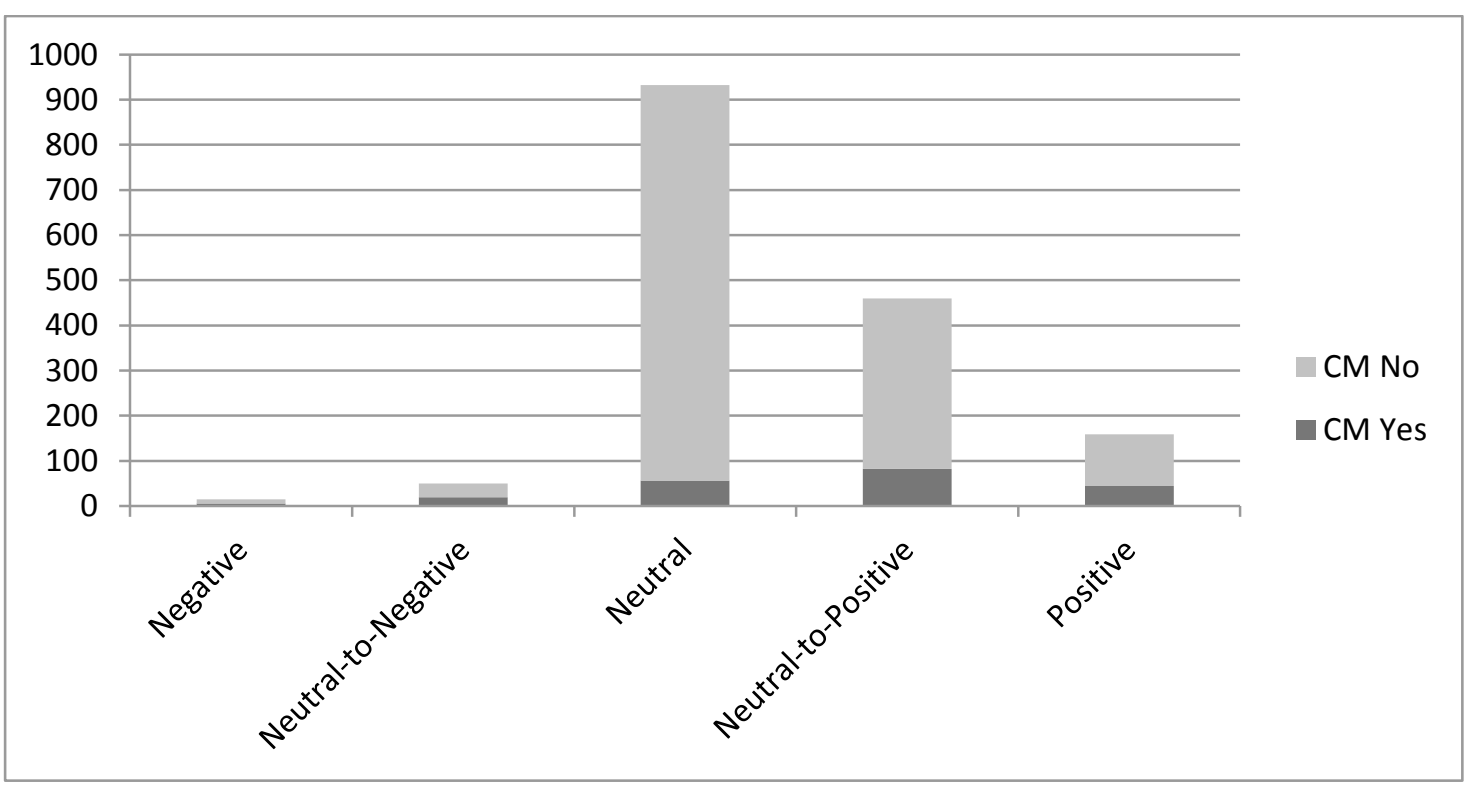

Our analysis of metaphors in each category identified a set of common images. Negative evaluations were often carried by metaphors that compared the EU's action to problematic progress - a restricted or obstructed movement, sometimes leading to bottlenecks. Sometimes forward movement came to an end without reaching a goal. Metaphors of personification sometimes compared the EU to an individual with bottomless appetite (i.e. never satisfied), or an ignorant challenged person not in the information loop, or a person experiencing negative (angry or frustrated) emotions. Rather surprisingly, the analysis identified an almost identical set of metaphors within the positive imagery categories - metaphors of movement and personification dominated. In this case, though, the movement forward was successful, with the EU making mighty progress while reaching milestones and ambitious goals. Metaphors of personification compared the EU to an able athlete who is kicking off sports games and leaping over barriers. It was even described as a champion. In a related set of images, the EU was constructed as an energetic, adventurous and strong individual - a pioneer, seizing opportunities, buzzing with excitement and providing support. Positive metaphorical images rested heavily on the side of personification and suggest that the reception registered the EU as a protagonist in the strategic story of' 'Sustainable Energy Europe'. Metaphors of forward movement suggest the narrative is future-oriented. Notably, our analysis also discovered a 
number of examples featuring conflicting images (both positive and negative) in the same tweets. Mixed evaluations, though not dominant, are argued here to be indicative that reception of the EU as an energy actor remains a challenging cognitive exercise. As a supranational actor, the EU remains an atypical producer of energy policies and diplomatic outcomes in an energy field still dominated by state-centred actors and practices.

\section{Discussion}

Our analysis demonstrated that 'Sustainable Energy Europe' is emerging as an appealing strategic narrative of the EU, resonating internally and externally. The 'story' of 'Sustainable Energy Europe' has all the necessary elements to classify it as a narrative according to Miskimmon et al (2013)'s configuration: actors, actions, intentions, settings and instruments. It features causes and effects and it is future-oriented. Thus, our comprehensive consideration of one relevant case study - social media communication of 'Sustainable Energy Europe' during the EUSEW 2013 - presents a promising dynamic for this narrative in terms of formation, projection and reception. The EUSEW was found to be formulated with clear goal of networking in mind, targeting both domestic and international receivers of the EU messages. The use of social media within it has possibly amplified the core objective of the EUSEW of networking and communicating among the EU and stakeholders. Further, our analysis of projection has revealed that the EU is among the most active authors formulating the message. The content analysis of that message revealed a particular frame projected to receivers - a frame of economic benefits arising from participation in the EUSEW and from engagement in sustainable energy field in general, and with Europe in particular. The analysis of reception showed that crucially for the narrative, the EU is recognised to be a valid actor undertaking action. The emphasis on economic pragmatism typical in the discussion of energy 
matters during the EUSEW has resulted in a heighted salience of business and political themes among ordinary citizens reactions to EU communications (people often 'vote with their wallets', and the field of energy is no exception). Indeed, plenty of ordinary citizens were found among those who received the EU's communications thus demonstrating popular appeal of the narrative. Positive sentiment was the most visible, suggesting the presence of a growing, positive attitude towards the EU as an energy actor. Finally, the norm of sustainability was the most recognised, which reflects that there is some recognition of the EU's 'normative' identity.

However, the study's findings also point to some potential challenges. The analysis of formation revealed an ambitious goal for the EU to reach both domestic and international audiences through the public diplomacy initiative of the EUSEW and to appeal to both state and non-state actors. This finding would suggest a need for a multi-faceted strategy to set up and run such an initiative effectively. How sophisticated and well thought through this strategy is remains an open question. On the level of projection, especially when it comes to selecting communicative highlights, it seems that the EU uses the same 'formula' for communicating 'Sustainable Energy Europe' as it has done in the past when communicating gender equality issues, for example. Rather than highlighting a perhaps contentious policy shift driven by a moral or ethical ideology, it has instead used its 'policy entrepreneurship' (Laffan, 1997) and primed the focus on the economic benefits or the likely economic consequences from not taking its suggested path. Through this pragmatic approach, arguably a normative agenda has emerged and is beginning to be successfully projected. On the level of reception, however, we observed a lack of dialogic communication. Instead, the patterns showed high volumes of 'one-off' messages of an often promotional character; a dominance of monologue vs. dialogue is often viewed as counterproductive for establishing true collaboration. Yet we agree with boyd et al. (2010) who have pointed to the value that can be derived from this type of Twitter communication. This analysis conceptualises RTs as an 
important part of Twitter conversations because, '[w]hile retweeting can simply be seen as the act of copying and rebroadcasting, the practice contributes to a conversational ecology in which conversations are composed of a public interplay of voices that give rise to an emotional sense of shared conversational context' (p. 1). For the 'Sustainable Energy Europe' narrative, then, all parts of this shared conversation are contributing to heightened salience of the message and therefore potentially greater engagement with it.

We also found that media stakeholders were much less present in our sample and thus engaging much less with EUSEW via Twitter. Yet, mass media are key in EU outreach to its citizens and experts and building a public sphere on issues around sustainable energy. Finally, the generally positive sentiment may have been triggered by a specific type of receiver group - the EUSEW participants. Bruns and Stieglitz (2012, p. 171) have noted previously that Twitter 'conversations' are most often shaped by a 'dedicated in-group'- a small, but vocal minority who dominate the dialogue. Our analysis would appear to confirm this argument in EU social media discussions on energy policy. As such, the EU could be described to be 'preaching to the converted' and not going beyond this to reach a wider audience.

These results could be of interest to scholars working in the fields of EU public policymaking and communication, as well as to practitioners - European political communication and social media experts, decision-makers and civil society across the various levels of EU governance. However, we must be careful not to make 'blanket' conclusions. Our paper presents a set of preliminary observations; one of the first empirical attempts to assess the creation, dissemination and reception of EU strategic narratives within a social media space. Future studies of the 'Sustainable Energy Europe' narrative should explore the views of EU policy and decision-makers, as well as non-EU, non-governmental organisers of the process in general, and EUSEW in particular. Also, while in our case communication of EU positions is occurring through the popular social media platform of Twitter, there are other media where projection of the narrative could take place. Future studies could examine and compare how 
the EU communicates in other media discourses, for example other social media platforms as compared to press or broadcast media. Finally, studies of reception element may also be enriched by incorporation of focus group interviews and opinion surveys.

In conclusion, we argue that despite its challenges, the EUSEW initiative remains a unique event in international energy relations. It is a public diplomacy undertaking, aiming at engendering positive attitudes towards the EU and its energy policies long-term. It is a 'normatively' based initiative and it is about networking between a supranational actor with state and non-state stakeholders, and even general public. This general public appeal remains a missing element in energy diplomacy conduct worldwide. The EU may be seen here as a pioneer and analysed further in future studies. 


\section{References}

Badouard, R., \& Monnoyer-Smith, L. (2013) Hyperlinks as Political Resources: The European Commission Confronted with Online Activism. Policy \& Internet 5(1): $101-117$.

Beetham, David and Christopher Lord (1998) Legitimacy and the European Union Essex: Addison Wesley Longman.

Bellamy, R. and Weale, A. (2015) Political Legitimacy and European Monetary Union: Contracts, Constitutionalism and the Normative Logic of Two-Level Games, Journal of European Public Policy, 22(2): 257-274.

Björkdahl, A., N. Chaban, J. Leslie and A. Masselot (eds), Importing EU norms? Conceptual Framework and Empirical Findings, Cham/Heidelberg/New York/Dordrecht/London: Springer, forthcoming 2015

boyd, D., Golder, S., and Lotan, G. (2010) Tweet, Tweet, Retweet: Conversational Aspects of Retweeting on Twitter, 43rd Hawaii International Conference on System Sciences, 110.

Bruns, A., and S. Stieglitz, (2013) Towards more systematic Twitter analysis : metrics for tweeting activities, International Journal of Social Research Methodology, 16(2): 91108.

Entman, R. (2003) Projections of Power: Framing News, Public Opinion, and U.S. Foreign Policy. Chicago: University of Chicago Press.

Eriksen, E. and J. Fossum, (2002), Europe in Search of its Legitimacy: Assessing Strategies of Legitimation, ARENA Working Papers, WP 02/38.

European Commission (2013), EU Sustainable Energy Week 2013: FAQ and main features, http://europa.eu/rapid/press-release_MEMO-13-596_en.htm, Accessed 29 September 2013. 
European Commission (2014), Plan D for Democracy, Dialogue and Debate, http://europa.eu/legislation_summaries/institutional_affairs/decisionmaking_process/a 30000_en.htm, Accessed 30 November 2014.

European Union (2013), Sustainable Energy Week 2013, http://www.eusew.eu/

Koskinen, K. (2013) Social media and the institutional illusions of EU communication. International Journal of Applied Linguistics 23(1): 80-92.

Laffan, B. (1997) From policy entrepreneur to policy manager: the challenge facing the European Commission, Journal of European Public Policy 4(3): 422-438.

Longo, M., \& Murray, P. (2011) No ode to joy? Reflections on the European Union's legitimacy. International Politics 48(6): 667-690.

Lord, C. (2000) Legitimacy, Democracy and the EU: When Abstract Questions Become Practical Policy Problems, Economic and Social Research Council Policy Paper 03/00

Macartney, H. (2013) The Debt Crisis and European Democratic Legitimacy. Basingstoke: Palgrave Macmillan

Manners, I. (2002) Normative power Europe: a contradiction in terms? JCMS: Journal of Common Market Studies 40(2): 235-58.

Miskimmon A, O’Loughlin B and Roselle L (2013) Strategic Narratives, Communication Power and the New World Order. New York: Routledge

Roselle, L, A. Miskimmon and B. O'Loughlin (2014) Strategic narrative: A new means to understand soft power, Media, War \& Conflict 7(1): 70-84.

Slaughter, A-M. (2011) Preface, in Porter, W. and Mykleby, M. (eds) A National Strategic Narrative. Washington, DC: Woodrow Wilson International Centre for Scholars, pp. 2-4.

http://www.wilsoncenter.org/sites/default/files/A\%20National\%20Strategic\%20Narrat ive.pdf Accessed November 30,2014. 
Thelwall, M., Buckley, K., and Paltoglou, G. (2011) Sentiment in Twitter Events. Journal of the American Society for Information Science 62(2): 406-418.

Traynor, I. (2014) 30,000 lobbyists and counting: is Brussels under corporate sway?, The Guardian, http://www.theguardian.com/world/2014/may/08/lobbyists-europeanparliament-brussels-corporate, Accessed 30 November 2014.

Van Noije, L. (2010) The European paradox: A communication deficit as long as European integration steals the headlines. European Journal of Communication 25(3): 259-272.

Verdun, A. (2013) 'Small States and the Global Economic Crisis: An Assessment' European Political Science, 12 (1), pp. 276-293.

Verdun, A. and T. Christiansen (2000) 'Policy-making, Institution-building and European Monetary Union: Dilemmas of Legitimacy' in C. Crouch (ed.), After the Euro: Shaping Institutions for Governance in the Wake of European Monetary Union, Oxford: Oxford University Press, pp. 162-78.

Vergeer, M., Hermans, L., and Sams, S., (2010) The Voter Is Only A Tweet Away Micro Blogging During The 2009 European Parliament Election Campaign In The Netherlands, 3rd Annual Political Networks Conference, Duke University. Vis, F. (2013) Twitter As a Reporting Tool for Breaking News. Digital Journalism 1(1): 2747.

\footnotetext{
${ }^{\mathrm{i}}$ Tweets were gathered using software developed and operated by Professor Mike Thelwall of the Cybermetrics Group at Wolverhampton University, to whom this project is indebted. Details of the Cybermetrics Group can be found at: http://cybermetrics.wlv.ac.uk/index.html. The project conformed with the University of Leicester Ethics Committee Regulations on data protection and privacy, and received approval before data gathering was undertaken. The project leaders also wish to express their sincere thanks to the three Twitter coders: Jasmin Lenz, Simon Lindmayer and Dorethea Stampfer, Technischen Universität Darmstadt post-graduate students.
} 
ii e.g. NGOs refers to WWF and two other country-specific NGOs; BRICS refers to several mentions of Russia, a couple of South Africa and a handful of China. India and Brazil were not visible; EU MS actors could mean the whole MS, in which case Germany was most visible, or representatives of those MS, like the city council of Barcelona. 